CHEMISTRY EDUCATION: RESEARCH AND PRACTICE

2003, Vol. 4, No. 1, pp. 83-96

SPECIAL SECTION: $6^{\text {th }}$ ECRICE $/ 2^{\text {nd }}$ ECCE
THE PRACTICE OF CHEMISTRY EDUCATION

(REPORT / POSITION PAPER)

Chemical education in Europe:

Curricula and policies

\author{
Raymond G. WALLACE \\ The Nottingham Trent University, Department of Chemistry \& Physics
}

\title{
RETHINKING THE EDUCATION OF CHEMISTS - THE ODYSSEY IS OVER, TIME FOR ACTION!
}

\author{
Received 1 August 2002; first revision 11 January 2003; \\ second revision 3 February 2003; accepted 4 February 2003
}

\begin{abstract}
Chemistry is a mature discipline with a distinguished pedigree and a long tradition, but times are changing and student numbers in chemistry are declining. The need for a reappraisal of what constitutes chemistry and a chemistry education at the beginning of the new millennium, is apparent. The paper examines some of the current issues surrounding chemistry and chemistry teaching and suggests ways in which we might go forward. A message of vision and imagination, applying a little of the ideals of Zarathustra in the setting of, '2001, A Chemistry Odyssey', is promulgated. [Chem. Educ. Res. Pract.: 2003, 4, 83-96]
\end{abstract}

KEY WORDS: chemistry courses; industry; sandwich education; image; popularity; declining numbers; degree; chemistry teachers; universities

\section{INTRODUCTION}

To begin my story, we must first of all consider why there is a need to rethink the education of Chemists. Reappraisal of educational activities is something that ought to be carried out from time to time, not least, as part of good educational practice. However this, in itself, is not the only reason why we should embark on such an activity. I believe there are a number of factors currently which have come together that make such a re-evaluation vital, at the start of the new millennium, if chemistry is to continue to maintain its undergraduate population, both now and into the future. I would suggest that the following are some of the issues which we should consider in the light of the present state of chemistry.

\section{THE ISSUES}

Self-interest - We could be out of a job! Perhaps a selfish reason but nonetheless a concern that lies not too far below the surface.

It is opportune - There have been a number of developments and initiatives in Europe over the last decade. Writing at the start of the last decade, the European Commission said: 'One feature of current skills shortage is the widespread lack of important generic skills and social skills such as quality assurance skills, problem-solving skills, learning efficiency, flexibility and communication skills. These are in addition to shortages of critical scientific and technological skills. In the 1990s the skills content of work is expected to increase. There will be a greater proportion of workers needing communications, language, management and 
organisational skills.' In relation to chemistry, a number of organisations have embarked on initiatives and written reports which have addressed some of the issues raised by the European Commission. The Alliance for Chemical Sciences and Technologies in Europe (AllChemE) has published a series of reports (AllChemE, 2002), resulting from seminars and workshops, which include:

- $\quad$ PhD Training in Chemistry in Europe (1997)

- University-Industry Interaction: Meeting the Needs of the Future through Chemistry and Chemical Engineering (1997)

- The changing marketplaces for chemistry and chemical engineering in Europe: emotion, education or economics (1998)

- Chemistry: Europe and the future (1999).

Again the European Chemistry Thematic Network (ECTN) have been active through working groups and reports which have included:

- (ECTN, 2002), Core Chemistry (1996/8) - update in light of Bologna Declaration (2001).

- Communication and Management Skills (1996/7).

- Post-University Training for Industrial Chemists (1997/8).

- Teaching and Learning: Practical Skills (1998/9).

- The Image of Chemistry (1998/9).

- Core Chemistry: Teaching Methods and Assessment (1999/0).

- Core Chemistry for the future (2000/1).

- Postgraduate Education (2001/).

The Bologna Declaration (ESHE, 2002) of June 1999 is set to have a major impact on the structure of European degrees. Some of its major proposals are:

- System of easily readable and comparable degrees and diplomas.

- Two main cycles, undergraduate \& graduate, access to second requires successful completion of first (minimum length 3 years).

- Establishment of an academic credit system (ECTS).

- Mobility.

- Quality assurance.

- European dimensions in higher education - curricular development, inter- institutional cooperation, mobility schemes and integrated programmes of study, training and research.

Additionally there is much activity (FECS, 2002) affecting the ways in which science (including chemistry) is being taught at secondary level across Europe. Chemistry teaching is moving towards context-based learning (Belgium, France and Germany), skills rather than facts (Hungary) and independent learning and projects (Portugal). Much effort is being put into in-service teacher training (Czech Republic, Denmark, Germany, Italy and Ireland).

Altruism - The experience of those that come after us should be better than that of ourselves. Lee Harvey, Head of the Centre for Research into Quality at the University of Central England, making a keynote presentation in Lund in Sweden in 1999 (Harvey, 1999) stated, "The primary purpose of higher education is to transform students by enhancing their knowledge, skills, attitudes and abilities while simultaneously empowering them as lifelong critical, reflective learners." The world is changing rapidly and will continue to change 
rapidly - higher education should play a role in accommodating, facilitating and leading change (rather than resisting change).

Decreasing popularity of Chemistry - This has been observed for a number of years now. By 'chemistry' I am of course referring to the subject that is, and was taught, within the traditional three major branches of inorganic, organic and physical chemistry. Evidence to suggest that large numbers of students now study mixed science degrees containing a large chemistry element, or alternative programmes which are essentially chemistry, has not been forthcoming. The Roberts review on the supply of high quality scientists and engineers in the UK (Roberts, 2002) comments that the 'relatively large and growing number of students studying scientific and technical qualifications', is largely down to increases in the numbers of students studying IT and the biological sciences.

In his public habilitation lecture 'Ein Plädoyer für Chemie' (Strazewski, 1999), Peter Strazewski from the University of Basel in 1996 lamented the rapid decrease in the number of students studying chemistry - in Switzerland and in Germany (where barely half as many matriculations were being recorded compared to a few years earlier). He observed in the USA it was the same and in many other industrialised countries. This was reiterated by Ronald Breslow (Breslow, 1996), the then President of the American Chemical Society. Undergraduate figures are still falling and causing national concern (Czech Republic, Denmark, Germany and the UK) (FECS, 2002). There is low interest in science studies by young people (Finland, Ireland, Germany) (FECS, 2002). Data from the UK spells out this decline in graphic terms (DFES 2002; HESA, 2002) (Figures $1 \& 2$ ). View this in the context of all undergraduate programmes in the UK (Figures $3 \& 4$ ).

As one can see from the graphs of Figures 3-4, the number of degrees awarded and the participation rates among the younger population have climbed rapidly since the late eighties. If we superimpose our chemistry numbers on the universal participation rates, we see the percentage growth in chemists was not nearly as great as for other subjects in general. Chemistry numbers started to decline when numbers for other subjects evened out, and when numbers for other subjects fell back a little during 1997-8, those for chemistry also fell, but have kept on falling. Contrast this with the recovery seen for subjects in general (Figure 5).

Why should there be this decline in the uptake of chemistry at university? If we put aside for the moment the fact that there has also been an increase in choice of subjects to study, I would suggest that there are three explanations: (a) the subject itself; (b) its image; (c) its career prospects.

\section{Subject}

Knowledge of chemistry is gained principally at school, mainly at secondary level (1419 age group in England). In a recently published report by the House of Commons Science and Technology Committee (House of Commons Science and Technology Committee, 2002) major problems were cited at this level that are putting students off studying science for life. These include:

- an inflexible assessment system;

- over-prescriptive curriculum (that lacks relevance and coverage of recent scientific developments);

- poor laboratory facilities;

- a shortage of technicians;

- poor careers advice. 


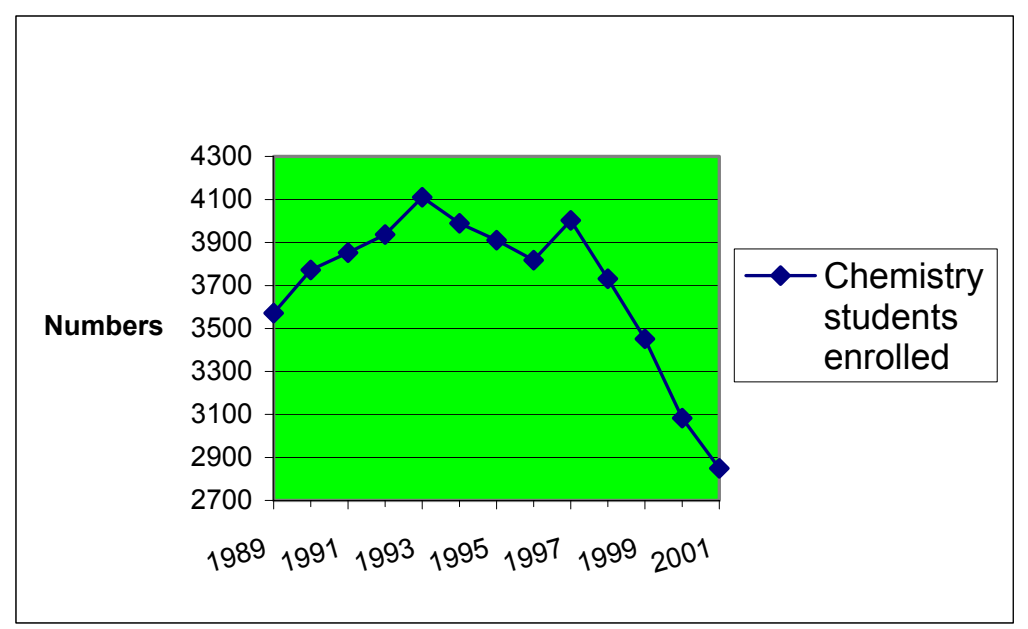

FIGURE 1. Change in chemistry numbers 1989-2001.

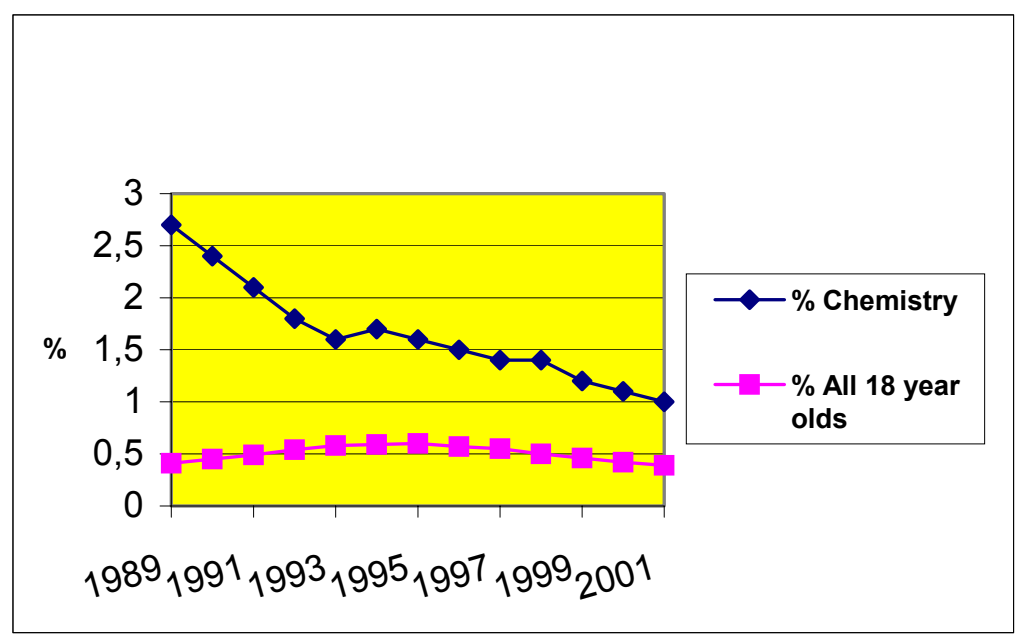

FIGURE 2. Percentage of students studying chemistry at university as (a) a \% of all subjects (b) as a \% of the 18 year old population as a whole.

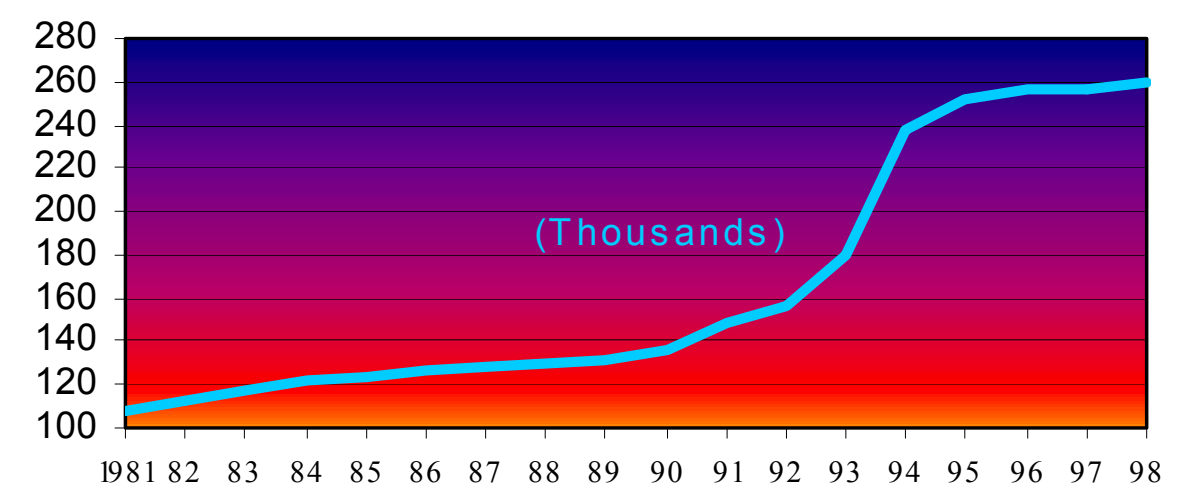

\section{Source: DFEE 1981-93, HESA 1994 onwards}

FIGURE 3. Higher education first degrees awarded 1981-1998. 


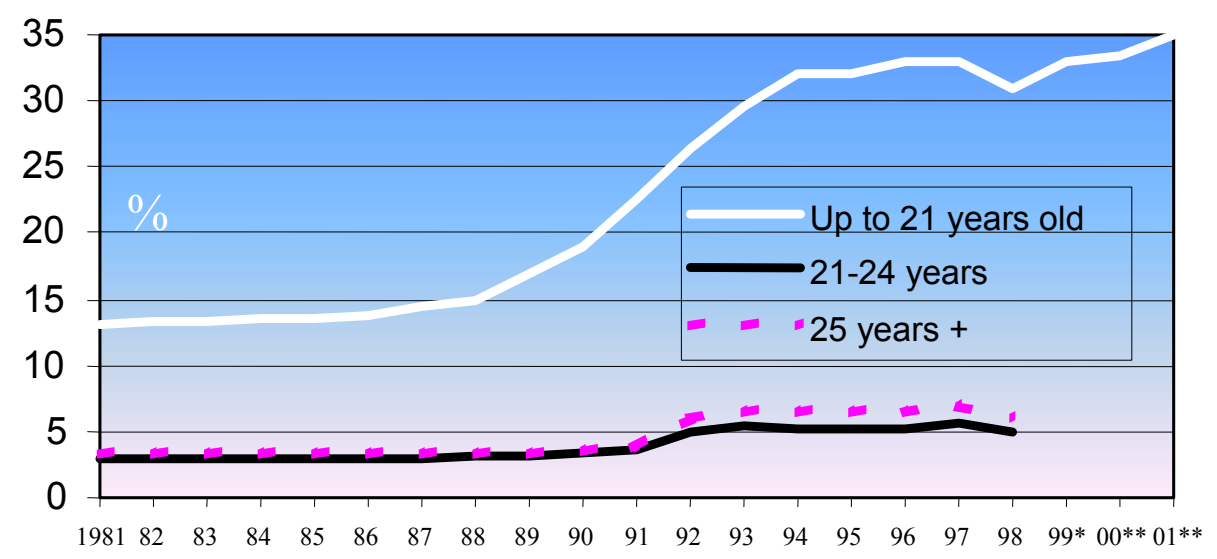

Source: DFEE *Provisional (upper end of range) **Projected

FIGURE 4. Rise in HE Participation in Great Britain.

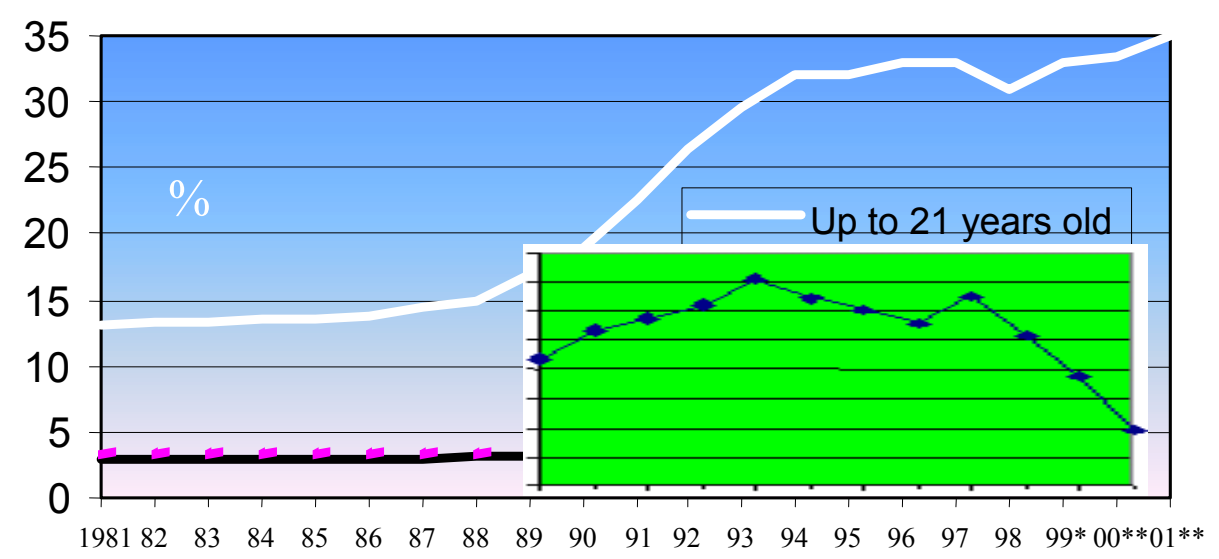

Source: DFEE *Provisional (upper end of range) **Projected

FIGURE 5. Rise in HE Participation in Great Britain (with chemistry graph superimposed).

For many who teach chemistry, particularly at the secondary school level, chemistry is no longer fun! Budget restrictions, and more importantly safety issues and legislation, have taken away the spontaneity and the 'let's try it and see' approach to experimentation. Add to this the curriculum 'which has to be covered' and 'the fundamentals which must be taught' both in schools and universities, give chemistry a bulkiness that detracts from its inherent fascination and the diversity of an all-permeating subject. The live issues and the varied and exciting applications that are still being developed, come late in the day of learning, by which time many students have 'switched' off and gone elsewhere. To those who look at the subject from the outside, it can seem a world of inaccessible technical terms and incomprehensible formulae. Further it suffers from the disadvantage that the invisible world of molecules is remote and as such cannot be perceived by the senses. Finally one should not forget the major influence played by the inspirational chemistry teacher as a motivator for a pupil to continue to study chemistry. I italicise 'chemistry teacher' deliberately since in the 
UK (excluding Scotland) there is an increasing trend for chemistry to be taught by nonchemists (Wallace, 2001; Roberts 2001) and this can only impact on pupils' perceptions of the discipline. The whole issue of the way chemistry is taught in schools and how it is portrayed, although not the focus of this paper, is something we ignore at our peril!

Image

Chemistry always appears to be dogged by a poor image (although interestingly not science or scientists (Royal Society of Chemistry, 2001). Advances go unreported or underreported. However there is excellent news coverage of every chemical accident. Other science disciplines have problems but the mud doesn't seem to stick! There is a dark side to all sciences. What Bhopal is to us, Chernobyl is to the physicist and BSE to the biologist. Science sections in the major media tend to feature medicine, biology and physics, not chemistry. Chemistry has a communication problem (Editorial, 2001). There is a lack of insight that chemistry is part of society in the GOOD sense rather than part of society in the bad sense. Chemists are very well capable of communicating but they haven't learned to communicate outwards. If this bad image is to be countered, we have to exploit the positive benefits.
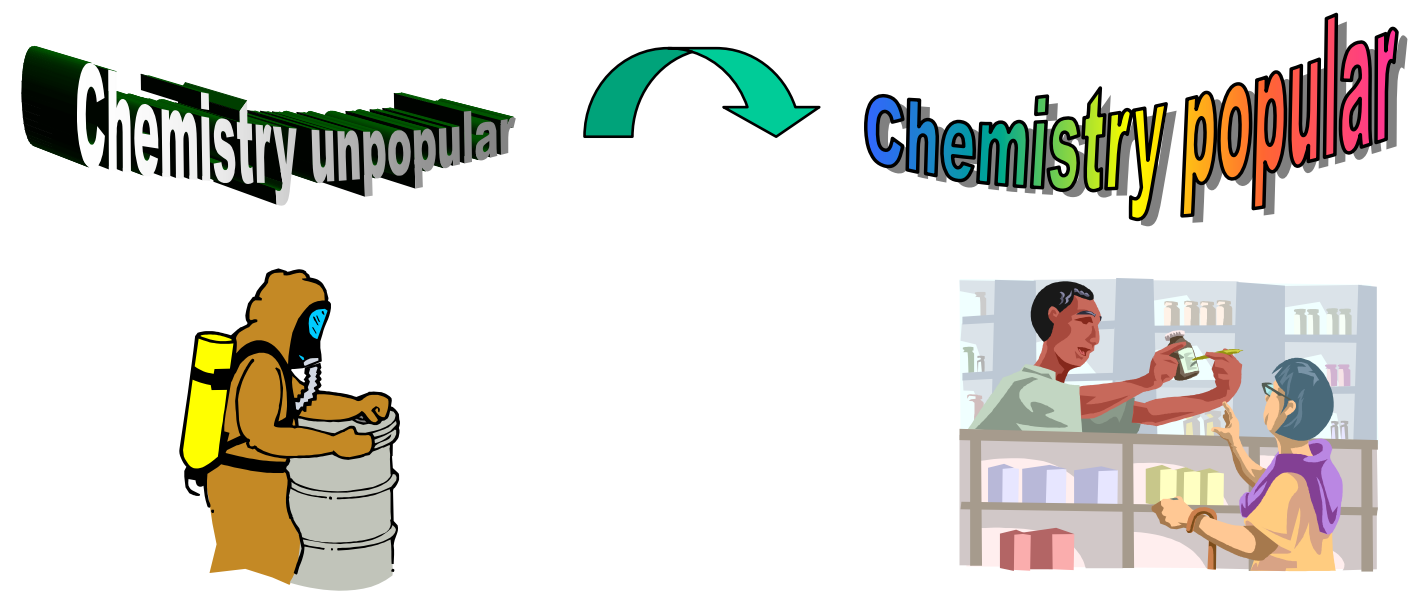

Medicines are seemingly not made by chemists. Fashion textiles figure prominently in our culture but are nothing to do with chemists. Healthy food is something of benefit, produced particularly without chemicals or chemical technology, the public would believe.

\section{Career prospects}

Chemistry must be seen to be a career provider. Long-term career prospects need to be good. Graduate salaries need to compare favourably with those of other occupations. Employment opportunities in chemistry should not fluctuate unduly. What are the likely predictions for chemistry employment for the immediate future? If we look at the world's largest economy, America, employment is expected to grow about as fast as average (10$20 \%$ ) for all chemistry and chemistry related occupations through to the year 2010 (Source: US Department of Labor (Occupational Outlook Handbook, 2002)). Job growth will be concentrated in drug manufacturing and in research, development, and testing services firms, it is predicted. If we look at the UK again, in $200038 \%$ of first degree graduates achieved their qualification in science and so graduating with a science degree is not seen as a disadvantage in the field of employment. In addition to the underpinning scientific theory, 
chemists develop well-honed analytical and numerical skills which complement their computer competency. These skills are highly sought after for financial, commercial and management graduate trainee positions.

Within science, courses increase and decrease in popularity (Independent, 2002), and this is to be expected, but if chemistry is to hold its position, students must be able to identify readily those advantages of having a chemistry degree.

Quality of applicants - Anecdotal evidence; it is difficult, for obvious reasons, to get academics to commit to print the fact that the quality of their own undergraduate applicants is falling, but most chemists working in higher education have stories to tell on this issue.

Chemistry's position among the sciences - Chemistry is at the heart of the sciences but we have allowed it to become 'highjacked'. Chemistry as a subject of our lives is not being recognised - 'the chemistry' belongs to somebody else (Editorial, 2001)! Take for example safety airbags in our cars. How do they work if it is not through chemistry? Watch television and it doesn't take long before you come across the role of the forensic scientist. This discipline relies heavily upon analytical techniques to identify, quantify, rationalise observations and so on, making use of basic chemistry as it does so. What is molecular biology, if it is not the chemistry of large molecules? This hijacking can be subliminal. Witness in UK (excluding Scotland) schools how the majority of students instead of taking chemistry and/or biology and/or physics at GCSE level (aged 16), take a GCSE 'double science' award, which comprises an amalgamation of the science subjects.

Re-examination of the relevance of the syllabus content - I have already alluded to the make up of the curriculum. This is not only an issue in the early years of learning. What if students eventually make it to university? Do they want more of the same: Facts first and then the interesting applications later? Almost certainly not; nor does this have to be the only option, either at school or at university level. Publications such as Salters' Advanced Level Chemistry (Heinemann publishers, 2000) and Our Chemical Environment (ST240) (The Open University, 1995) are excellent examples of where contexts and applications of chemistry are used as the vehicle for teaching chemistry in an exciting and stimulating way. The curriculum in itself can be a difficult and controversial issue, particularly when much work has already been undertaken in its development, as for example with the core European university level syllabus for chemistry (ECTB, 2002). This project addresses almost exclusively, traditional chemistry content which is taught currently in European universities, and is playing a valuable role in attempting to harmonise chemistry programmes. If we now decide to alter in a radical way how that curriculum is delivered, then it may not be possible to cover all of the subject matter, and indeed other topics that have been set aside may need to be re-included. Change always has ramifications. 'Traditional' should not mean 'set in history'. 'Traditional' in some ways is synonymous with 'the subject' and I would submit that there a more radical way of delivering chemistry, where chemistry is used as vehicle for delivering a scientific education. Clearly there is still a need for a core of traditionally educated chemists for the foreseeable future and supply should attempt to match demand. However college and university chemistry departments must not be tied to past definitions that exclude some of the most exciting new chemical areas (Adam, 2001) for these chemists. The alternative, chemistry, the vehicle, would be an approach where the emphasis is more on scientific method and how it can be used and applied to broader and indeed seemingly unrelated areas. It would seek to look at concepts in a wider arena. For instance one might look and compare accuracy and precision in measurement, the concept of the mole, how 
structure at the molecular level can influence properties of a substance and the concept of multifarious behaviour - the electron as a particle and a wave.

Parallels to these could be the validity of data on a survey concerning health, comparability of weighting of time allotted to tasks, micro and macro economics and understanding seemingly different patterns of behaviour in humans, for example.

The traditional educational pathway - Involves abrupt transitions at the interfaces - school to university to employment - and has serious shortcomings. Transitions are a source of apprehension and are unsettling. At the second stage (university) there is a failure to develop 'employability' skills. The pathway for the majority of students (who spend their education full-time at the university) does not give the individual chance to reflect on his/her studies, particularly as to how chemistry is used in the real sense. Application of theory comes late in the day. It denies opportunity to develop confidence. The relationship between higher education and employment has been discussed at length by Harvey (Harvey, 1999) amongst others. He concludes that the need for the development of reflective empowered learners, which he asserts are needed by industry and commerce, raises fundamental questions about traditional forms of teaching in higher education and the priorities of higher educational institutes and governments. This issue has concerned the government in the UK and it recently published a report (Department for Education and Skills, 2002) of a working party it set up, whose brief was 'To consider options and recommend a strategy for increasing the full range of opportunities for all Higher Education (HE) students to undertake work experience, including paid and voluntary work, in a way that better enhances their employability'. Ways in which transitions can be made more seamless, particularly into the world of work are important as they make for a more efficient and smoother road to a career. Although the majority of students these days have some for of part-time or vacation employment, the nature of the context of this work is quite different from ultimate employment, which constitutes a career. Nonetheless such employment does provide insight into the modus operandi of the commercial world. More thought needs to be given in my view to these transitions and we may need to ask additional questions. For instance, is school chemistry trying to achieve different goals to that of university chemistry and therefore is the transition more marked than it needs be? At the university level, what are we doing to prepare students for the varied situations that they will encounter in permanent employment?

The reader may have additional thoughts on why we should rethink the education of chemists. My list is not exhaustive. However my contention is that we ought to think about these issues.

As in all aspects of human relations, more can be achieved through cooperation, than working alone. We must turn therefore to the needs of the ultimate consumers of universities' products: industry and commerce. Some of the things that employers say they want are:

- Chemists, but with additional skills.

- Bright graduates; (they tend to use grades, rather than subject area, as a first filter); the majority of vacancies filled by graduates do not require someone from a specific discipline.

- Graduates with work experience.

Over commence and industry as a whole employers say that graduate attributes are more important in the recruitment process than the graduates' degree subject. For example many large accountancy and management-consultant firms seek history, classics, social science or chemistry $\&$ physics graduates rather than accountants. Software firms are not looking for computing specialists. They need IT-literate people who can communicate and work in 
teams. A sales manager of a large multinational reprographic equipment manufacturer, speaking of work experience stated, "Those that have done the year placement do come over better. They fit into the organisation a lot better, they are not so overawed by having managers around and stuff like that. They are much easier with themselves.... Usually students who have been out for a year are a bit more confident, they are a bit easier with their surroundings and not as tentative."

In the 1970 s employer graduate specifications were:

- communication skills;

- numeracy;

- self-confidence;

- $\quad$ self-discipline;

- problem solving;

- analysis;

- interpersonal skills;

- knowledge;

- intelligence.

Intelligence has been augmented at the turn of the new century with:

- ICT skills;

- team working;

- flexibility.

Today, problem solving has become creative problem solving. Additionally, risk-taking has become a key attribute. There is now much less emphasis on knowledge and far more emphasis on willingness to continue learning. In short employers want adaptive graduate recruits. We can attempt to engender these skills and attributes within our degree courses but what we can't do it simply through TEACHING CHEMISTRY ALONE! Better to use (and co-operate with) industry to provide a vehicle for bringing about these transformations in graduates. How can this be addressed? The classical way is through co-op education (or 'stage', 'practikum', 'industrial training' or 'internship' as it is alternatively called). In the sciences this almost invariably involves giving students experience of practical work associated with their science discipline in a science based industry. There are many examples of good practice, established programmes or moves to introduce it. It probably has its origins in North America. Japanese Institutes of Technological Sciences (Gijutsu Kagaku Daigaku) have 5 months practical training periods. It is well established in the UK, Ireland, France (IUTs), Germany/Austria (Fachhochschule), and Finland (Technical Universities). There have been programmes funded by the European Union, in Greece (Institutions of Technological Education) and Hungary. There is a limited amount in Spain (Prácticas en la Industria), Sweden and the Netherlands (HBO establishments -Hoger Beroepsonderwijs). So, let us put it under the microscope. Again I turn to the UK for facts and figures (Hunt, 2001). Within chemistry we find the following:

- 600 students per year are involved (estimate) in sandwich education.

- $15 \%$ of graduating chemists have experienced some form of industrial training (nationally $11-14 \%$ of all subjects).

- 81 Higher Education Institutions provide 1278 chemistry degree courses (figures for 2000). 
- 62 Higher Education Institutions offer courses with an element of industrial experience survey identifying $~ 100$ courses, (Association for Sandwich Education and Training web site (ASET, 2001) suggests there are possibly in total $\sim 220$, ie $\sim 17 \%$ of courses.

Opinions in answers to questions (responses from 32 departments):

- Is industrial training decreasing/increasing? Answer: No clear trend.

- Does it improve subsequent employability? Answer : 69\% thought yes.

- Top six skills thought to be acquired: team working (91\%); practical skills $(84 \%)$; oral communication (81\%); time management (81\%); general chemical knowledge (78\%); presentation skills $(78 \%)$;

- Other skills thought to be acquired: specific chemical knowledge; report writing; commercial awareness; problem solving; project planning.

Traditionally we concentrate on providing students with context based practical experience of the subject discipline. However it is almost certain that the interpersonal and related skills acquired in industry are equally, if not more important, in the context of a career, particularly as the majority of chemists do not become ultimately 'bench chemists' or 'bench scientists' (Mason, 1998). It is one thing to suggest that the school to university to employment model may be wrong, but is there any evidence that students generally fare better, not least in their academic results, if they follow a sandwich pathway? Data on this issue are severely lacking in the literature but figures from my own Department suggest that this is true. (Note: recent research by this author (Wallace, 2002) has uncovered similar findings in many UK chemistry departments). Of course a number of other factors may well influence student performance, such as employer filtering of the better students through interview and these are discussed in the paper (Wallace, 2002). The figures below (Figures 6-9) show first degree outcomes, over a four year period, for students following a sandwich (with) or full-time pathway (without). Data is also shown for national degree outcomes (all subjects) (Figure 10).

Despite this endorsement for industrial training, nationally, for the previous three years 1995-1997 the numbers of students undertaking a sandwich placement had declined in all subject areas except languages (Harvey, 1999) (see Table).

It is important to stop to consider why this should have been the case, since if one wishes to promote the benefits of such an educational mode, factors which discourage its adoption should be examined so that colleagues are aware of the pitfalls. Most I submit were peculiar to the UK at the time:

- pressure on teaching staff as a result of a rapid expansion of the higher education system;

- lack of resourcing for sandwich courses;

- lack of prestige for staff;

- pressure from government to shorten courses;

- student debt.

It would seem that there is no possibility of reversing the decline in the UK in much less than 10 years unless drastic policies, backed up by funding, are introduced (Freemantle, 2002). Employability is battling against academic culture. 

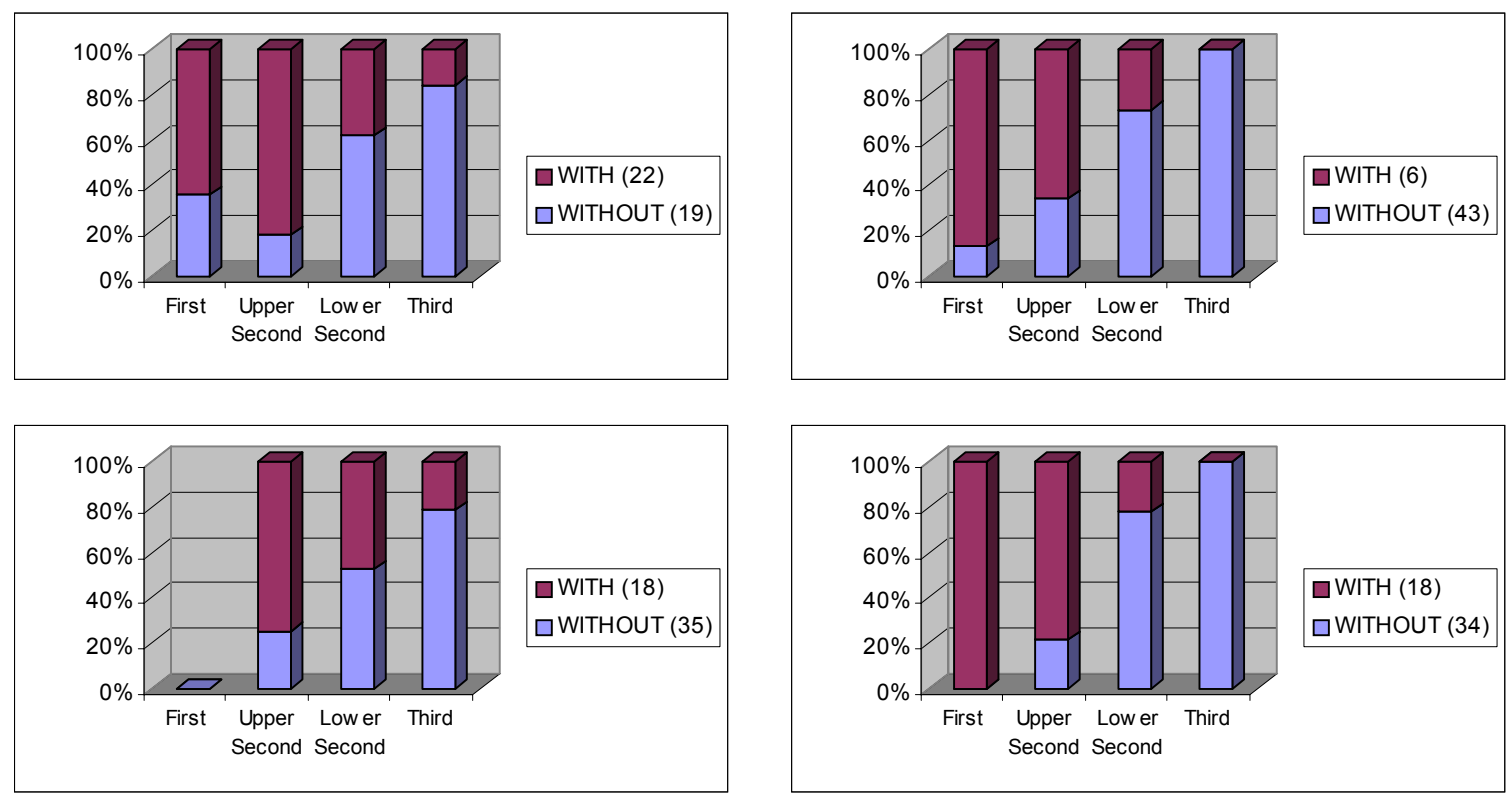

FIGURES 6-9. Degree outcomes Nottingham Trent University Chemistry Department 1998-2001.

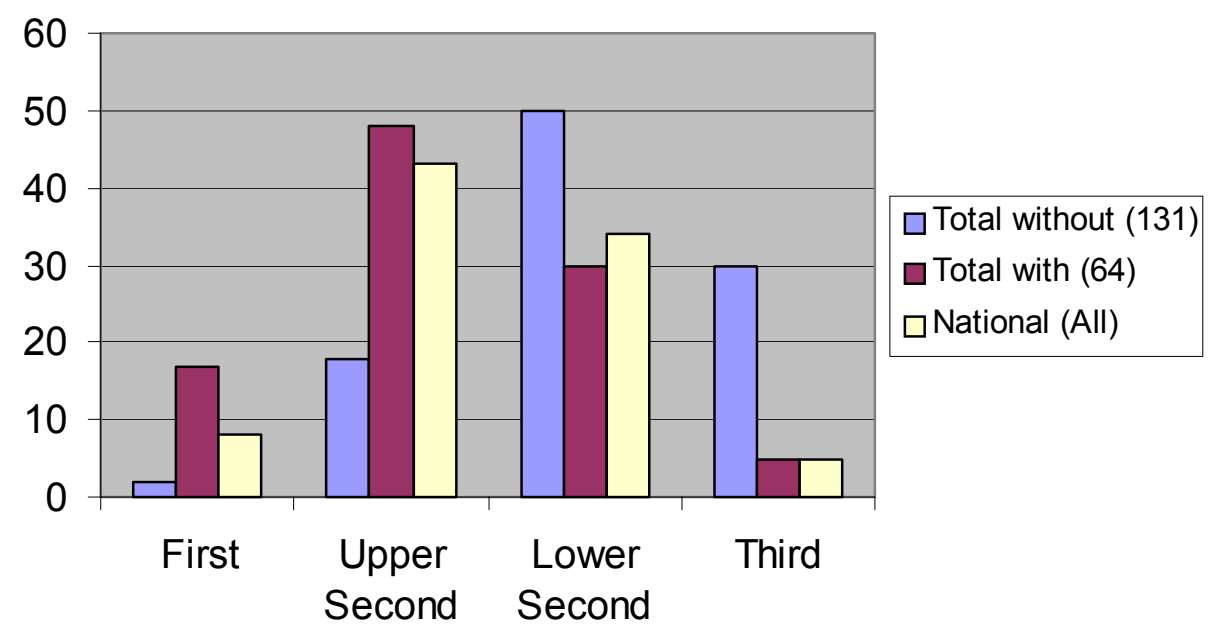

FIGURE 10. Degree outcomes Nottingham Trent University Chemistry Department 1998-2001 compared nationally with all subjects.

TABLE. Percentage change in the number of students sandwich training in the years 1995-97.

\begin{tabular}{cc}
\hline Subject & Percentage change \\
\hline Social, economic, and political studies & -27.5 \\
Mathematical sciences & -20.8 \\
Physical sciences & -17.6 \\
Engineering and technology & -11.7 \\
Computer science & -9.7 \\
Creative arts and design & -9.4 \\
Subjects allied to medicine & -9.2 \\
Business and administrative studies & -8.9 \\
Biological sciences & -7.6 \\
Architecture, building and planning & -5.1 \\
Agriculture and related subjects & -4.5 \\
Languages & 0.0 \\
\hline
\end{tabular}




\section{SOME RECOMMENDATIONS}

What then do we need to do within the chemical community? I suggest that we must to do the following:

- consolidate;

- metamorphose;

- diversify;

- rebadge;

- think radically.

My first tenet is that within Europe we should consolidate, expand and encourage the introduction of co-op education based around traditional chemistry. This can take the form of a simple industrial experience where the student spends a short period in industry, to fully integrated programmes, where the industrial period is assessed and is supplemented with concomitant academic study and makes a major contribution to the degree outcome. This is possible within the $3+2$ system which is emerging BUT SYLLABUS CONTENT HAS TO GO! Within this we should metamorphose and diversify and rebadge. By this I mean as examples:

- Metamorphose:

- structure \& bonding becomes chemical architecture;

- atomic structure becomes the chemical micro world.

- Diversify into:

○ biotic chemistry;

○ supramolecular chemistry.

- Rebadge chemistry as:

○ molecular science;

- molecular studies.

This is not simply a matter of semantics but of perception (Adam, 2001). Chemists need to send the right signals to potential students. These are exciting worlds, populated by chemists.

My second tenet is that we should introduce new courses that are covertly chemistry, integrated with work experience, having themes which identify them with the everyday world (see for example (Ball, 2001)) and are organised by chemists. Examples of covert chemistry courses could be, 'science and art of fashion', 'science and advertising' and 'entertainment and leisure - the science of recreation'.

My third tenet is that people whom we train to become school chemistry teachers should have industrial experience as part of their training. This last tenet is perhaps the most important for chemistry's long term survival. Teachers are pupils greatest source of inspiration. Trainee teachers' experience in industry \& commerce would give them a deeper appreciation of chemistry's application in peoples' daily lives. They will speak from personal experience - not from what they have read!

These recommendations are not without their difficulties. For example, if all students were to have a period of a subject based work experience, it would put a huge strain on employers. Academics are reluctant to give up subject material to reduce syllabus content and so on. But if we never try, nothing will ever happen..... 
NOTE: The author wishes to acknowledge the work taking place in Portugal, supported by the European Social Fund, for improving the transition from school to the labour market through developing more and better 'sandwich courses' and by providing alternative education and training routes for those who fail at school and also to thank the University of Aveiro which provided the venue for the plenary presentation on which this paper is based.

CORRESPONDENCE: Raymond G. WALLACE, Department of Chemistry \& Physics, The Nottingham Trent University, Clifton Lane, Nottingham NG11 8NS, UK; fax: +44 115848 6636; e-mail: ray.wallace@ntu.ac.uk

\section{REFERENCES}

Adam, D. (2001). What's in a name? Nature, 411, 408-409.

AllChemE website (2002). AllChemE publications. [http://www.chemsoc.org/networks/enc/allcheme_pubs.htm]

ASET website (2001). Database. [http://dh1a-2.coventry.ac.uk/aset/program.htm], site currently suspended, contact email: aset@aset.demon.co.uk]

Ball, P. (2001). Stories of the Invisible. Oxford University Press.

Breslow, R. (1996). Interesting times for chemistry. Chemical and Engineering News, 74, 1.

DFES (formerly DFEE) Website (2002). Department for Education and Skills. [http://www.dfes.gov.uk/statistics/]

Department for Education and Skills (2002). Work related learning report. DFES Publications, Nottingham, February 2002.

ECTN website (2002). European Chemistry Thematic Network working groups. [http://www.cpe.fr/ectn/Working\%20groups.htm]

Editorial (2001). A discipline buried by success. Nature, 411, 399.

ESHE website (2002). The European space for higher education. [http://www.unige.ch/cre/activities/Bologna\%20Forum/Bologna_welcome.htm]

FECS website (2002). Federation of European Chemical Societies annual reports. Annual Report 2000. (Website only houses summary, Annual Report available from the FECS Secretary, Ms E. K. McEwan at the RSC, email: mcewane@rsc.org.) [http://www.chemsoc.org/networks/enc/fecs/fecspubs.htm]

Freemantle, M. (2002). U.K. Chemistry under pressure. Chemical and Engineering News, 80, 31-36.

Harvey, L. (1999). New Realities: the relationship between higher education and Employment. Paper presented to the European Association of Institutional Research Forum, Lund, August 1999. [http://www.uce.ac.uk/crq/publications/cp/eair99.html]

Heinemann publishers (2000). Salters' advanced chemistry: Chemical storylines - Salters' Advanced Chemistry. Heinemann Ed 2000; Salters' advanced chemistry: Chemical ideas Salters' Advanced Chemistry. Heinemann Ed 2000; Salters' advanced chemistry: Activities and assessment pack. Salters' Advanced Chemistry.Heinemann Ed 2000.

HESA website (2002). Higher Education Statistics Agency. [http://www.hesa.ac.uk/]

Hunt, M. H. (2001). Education and training in chemistry - undergraduate degree courses and the provision of industrial training. Report prepared for the Royal Society of Chemistry Education Division Council, contact Ms L. Hart at the RSC, email: hartl@rsc.org.

Independent Newspaper website (2002). Science courses: the growers and slowers (2001). [http://www.independent.co.uk/story.jsp?story=88908] 
Mason, G. (1998). Change and Diversity: The challenges facing chemistry higher Education. The Royal Society of Chemistry, London, March 1998.

Occupational Outlook Handbook (2002). Occupational Outlook Handbook 2002-03 Edition, U.S. Department of Labor, Bureau of Labor Statistics. [http://www.bls.gov/oco/home.htm; location of article http://www.bls.gov/oco/ocos049.htm]

Roberts, G. (2002). SET for success: the supply of people with science, engineering and mathematics skills. The report of Sir Gareth Roberts' Review, April 2002, London, HM Treasury, 2002. [http://www.hm-treasury.gov.uk/documents/enterprise_and_productivity/ research_and_enterprise/ent_res_roberts.cfm]

Roberts, K. (2001). Look who's teaching chemistry, Education in Chemistry, $38,3$.

Royal Society of Chemistry (2001). What does the public think of science and scientists? The Royal Society of Chemistry, Chemical Science Issues, No. 5, September 2001, London.

Strazewski, P. (1999). A Pleading For Chemistry. European Chemical Chronicle, 4. ((1997) original German text Chimia, 51, 69-75.)

[http://web191.petrel.ch/ecc/contents/issues/vol4is1/a plea/pleafull.html]

The Open University (1995). Our chemical environment (ST240), Books 1-4, The Open University 1995.

Wallace, R. (2001). The need for vision. Education in Chemistry, 38, 65.

Wallace, R. G. (2002). A Sandwich year can seriously damage your chances of obtaining a poor degree! Proceedings of the ASET European Conference, Integrating Work and Learning in Europe, Cambridge, September 2002, 70-74. 